\title{
ESTATUTO DO IDOSO: UMA ANÁLISE DOS DIREITOS DO CONSUMIDOR HIPERVULNERÁVEL À LUZ DOS DIREITOS DA PERSONALIDADE
}

\author{
Oscar Ivan Prux ${ }^{1}$ \\ Diego Castro de Melo ${ }^{2}$ \\ Alexandre Herrera de Oliveira ${ }^{3}$
}

Resumo: A Constituição Federal previu a Dignidade Humana como Fundamento da República Federativa. O estatuto do idoso, publicado no ano de 2003, visou uma proteção ainda maior e mais específica para os idosos. Assim, por intermédio de uma abordagem dedutiva e comparativa, com pesquisas essencialmente bibliográficas e documentais, o presente artigo busca analisar a situação do idoso enquanto consumidor hipervulnerável e eventuais práticas abusivas contra esse grupo social. Em específico, no que tange a contratos de empréstimos bancários, analisando a importância do direito do consumidor para assegurar os direitos da personalidade do idoso enquanto consumidor.

Palavras-Chaves: Dignidade Humana; Direitos da Personalidade; Proteção do Consumidor; Idoso; Hipervulnerável.

\section{STATUS OF THE ELDERLY: AN ANALYSIS OF THE HYPERVULNERABLE CONSUMER IN THE LIGHT OF PERSONALITY RIGHTS}

Abstract: The Federal Constitution provided for Human Dignity as the Foundation of the Federative Republic. The statute for the elderly, published in 2003, aimed at an even greater and more specific protection for the elderly. Thus, through a deductive and comparative approach, with essentially bibliographic and documentary research, this article seeks to analyze the situation of the elderly as a hypervulnerable consumer and possible abusive practices against this social group. Specifically, with regard to bank loan contracts, analyzing the importance of consumer rights to ensure the rights of the elderly person as a consumer.

Keywords: Human Dignity; Personality Rights; Consumer Protection; Old man; Hypervulnerable.

\footnotetext{
*Pós-Doutor em Direito pela Universidade de Lisboa (Portugal); Doutorado em Direito das Relações Sociais pela Pontifícia Universidade Católica de São Paulo (2001). Mestrado em Direito das Relações Sociais pela Universidade Estadual de Londrina (1995). Graduação em Direito pela Universidade Estadual de Londrina (1976). Graduado em Ciências Econômicas pela Fundação Faculdade Estadual de Ciências Econômicas de Apucarana (1988) e Especialização em Teoria Econômica. Membro e Titular Fundador do Centro de Letras Artes e Ciências do Vale do Ivaí. E-mail: prux@uol.com.br

*Mestrando em Ciências Jurídicas pelo Centro Universitário de Maringá - UNICESUMAR. Especialização em Direito Constitucional. Especialização em Direito Público com ênfase em Gestão Pública. Especialização em Direito Processual Civil. Técnico Legislativo Nível Superior Assembleia Legislativa de Mato Grosso. E-mail: diego_cmelo@hotmail.com

*Mestrando em Ciências Jurídicas pelo Centro Universitário de Maringá - UNICESUMAR; Especialista Lato Sensu em Direito Constitucional pela Faculdade Afirmativo, Procurador Legislativo e Advogado. E-mail: alexandre_advogado@hotmail.com
} 


\section{INTRODUÇÃO}

A Constituição Federal elencou no artigo $1^{\circ}$, III, a Dignidade Humana como um dos fundamentos da República Federativa do Brasil. Tal redação demonstra por si só o viés protetivo chancelado pelo Constituinte.

Nesse contexto, no ano de 2003, a Lei 10.741 conhecida como Estatuto do Idoso, adveio como forma de garantir ainda mais proteção à dignidade das pessoas que já alcançaram no mínimo 60 anos de idade. A par dos direitos fundamentais inerentes à pessoa humana, lhes foi conferida a proteção especial estabelecida no estatuto com vistas a assegurar-lhes a preservação de sua saúde física e mental e seu aperfeiçoamento moral, intelectual, espiritual e social, em condições de liberdade e dignidade.

Inobstante tais previsões legais, esse segmento de pessoas que por sua própria natureza, em certas relações de consumo, são afetadas por vulnerabilidade agravada (hipervulnerabilidade), por vezes são vítimas de condutas irregulares de fornecedores. A principiar dentre outras pelas praticadas por intermédio de publicidades agressivas algumas enganosas, outras abusivas. E nesse aspecto se pode destacar as que se valendo da falta de conhecimento técnico do consumidor idoso, o induzem a contratar empréstimos inoportunos (por um inopinado simples clicar em máquina de autoatendimento para o qual ele não foi treinado para utilizar) ou com condições desconformes com sua capacidade de pagamento, ou até com encargos abusivos e/ou outras obrigações desmesuradas.

Daí advém à importância do Código de Defesa do Consumidor que em diálogo das fontes com o Estatuto do Idoso, igualmente labora para o respeito aos direitos da personalidade de consumidores idosos nas relações de consumo, incluindo proteção à dignidade, honra, imagem, etc.

O presente artigo versará acerca da proteção constitucional e infraconstitucional do idoso na condição de consumidor enquanto hipervulnerável abordando práticas abusivas que frequentemente ocorrem contra essa parcela da população. Para alcançar tal intento, o método aqui empregado será o da análise da literatura jurídica, com uma abordagem dedutiva amparada em pesquisas essencialmente bibliográficas e jurisprudenciais, assim como de doutrinas e conhecimentos relacionados ao tema. 


\section{A PROTEÇÃo AOS DIREITOS DA PERSONALIDAdE E A PROTEÇÃo CONSTITUCIONAL DO IDOSO}

Antes de adentrar a análise dos ditames constitucionais acerca da Dignidade Humana, convém trazer à baila o contido na Declaração Universal dos Direitos Humanos, emanada em 1948, poucos anos após o fim da segunda guerra mundial. Passado aquele período de horrores, mortes de civis, incluindo crianças, idosos, o holocausto e o assassinato em massa de inocentes, foi estabelecido um marco no que tange à proteção do ser humano, a partir de então alocado como foco primordial do direito.

Nesse sentido, a mencionada declaração (Assembleia Geral da ONU) logo em seu artigo I estabelece "Todos os seres humanos nascem livres e iguais em dignidade e direitos. São dotados de razão e consciência e devem agir em relação uns aos outros com espírito de fraternidade." Desta forma, deixou evidente essa preocupação em positivar esses direitos na legislação internacional.

Acerca do tema, constituindo-se em marco referencial para proteção de vários dos direitos da personalidade, a convenção americana sobre direitos humanos, também conhecida como pacto de San José da Costa Rica, estabeleceu: “Artigo 11. Proteção da honra e da dignidade, 1 . Toda pessoa tem direito ao respeito de sua honra e ao reconhecimento de sua dignidade."

Feito essa breve remissão a algumas normas internacionais que regem o tema e sem a pretensão de esgotá-lo, no que tange ao direito pátrio a dignidade da pessoa humana, a partir de 1988, foi alavancada a princípio fundamental da República Federativa do Brasil, logo no artigo $1^{\circ}$ da Constituição Federal.

Marinoni explica que assim como ocorreu no âmbito da evolução constitucional internacional, também no direito constitucional positivo brasileiro a dignidade da pessoa humana tardou a ser objeto de reconhecimento, muito embora o Brasil, em comparação com a absoluta maioria das demais ordens constitucionais, tenha inserido a dignidade de maneira relativamente precoce em um texto constitucional (SARLET; MARINONI; MITIDIERO, 2018, EBOOK pg. 414).

Conceituar o instituto dignidade humana, ante sua complexidade e alcance infindável nas relações sociais não é algo simples. 
Ricardo Castilho leciona que os valores constitucionais atribuem parâmetros para aferição da validade, da eficácia e da legitimidade das normas jurídicas. Nesse contexto, o princípio da dignidade humana revela toda sua força. Como fundamento de nosso Estado Democrático de Direito (artigo $1^{\circ}$, III, da Constituição Federal), ele serve de substrato às formulações legislativas e como baliza para o julgador (CASTILHO 2018, EBOOK, pg. 296).

Bernardo Gonçalves Fernandes explica que dignidade da pessoa humana é erigida à condição de meta-princípio. Por isso mesmo, esta irradia valores e vetores de interpretação para todos os demais direitos fundamentais, exigindo que a figura humana receba sempre um tratamento moral condizente e igualitário, tratando cada pessoa como fim em si mesma, nunca como meio (coisas) para satisfação de outros interesses ou de interesses de terceiros (FERNANDES, pg. 310).

Daniel Sarmento (SARMENTO, 2016, pg. 58) por sua vez, expõe que a dignidade da pessoa humana está consagrada com destaque na Constituição de 1988 , no artigo. $1^{\circ}$, inciso III, que a invoca como "fundamento da República", sendo também citada em outros preceitos mais específicos (artigos. 170; 226, $\S 6^{\circ} ; 227 ; 230$ ). O Brasil, ademais, ratificou e incorporou ao ordenamento jurídico vários tratados internacionais de direitos humanos que contêm referências à dignidade.

Além da previsão acerca da dignidade humana, o constituinte previu ainda a proteção mais específica para os idosos, conforme ditames expostos nos artigos 226 e 230 da Constituição Federal.

Analisando o referido artigo 230, Canotilho explica que a inserção da tutela específica à pessoa idosa no texto constitucional decorreu de duas circunstâncias significativas: a primeira, a preocupação do constituinte com a proteção das pessoas vulneráveis, portadoras de algum tipo de fragilidade; a segunda a necessidade de se atribuir tutela jurídica a uma parcela cada vez maior da população, considerando-se que a expectativa de vida do brasileiro está em constante crescimento (CANOTILHO, 2013, EBOOK, pg. 4651).

Importante salientar que o artigo 230 da Constituição Federal consagrou o princípio da solidariedade impondo à família e à sociedade o dever de amparo aos idosos. Alexandre de Moraes explica que mais do que reconhecimento formal e obrigação do Estado para com os cidadãos da terceira idade, que contribuíram para seu crescimento e desenvolvimento, o absoluto respeito aos direitos humanos fundamentais dos idosos, tanto em seu aspecto 
individual como comunitário, espiritual e social, relaciona-se diretamente com a previsão constitucional de consagração da dignidade da pessoa humana (MORAES,2016, EBOOK, pg. 1345).

Destaca-se que os preceitos referidos se articulam com outros dispositivos constitucionais, especialmente no campo dos direitos sociais e da ordem social, como dão conta os direitos à saúde, previdência e assistência social, os dois últimos inclusive com particular aplicação aos idosos.

\subsection{Do Estatuto Do Idoso E Os Direitos Da Personalidade}

A velhice, por si só, não é causa de incapacidade, o que por certo o legislador pátrio deixou evidente na legislação. Os artigos $3^{\circ}$ e $4^{\circ}$ do Código Civil elencam os tipos de incapacidade absoluta e relativa, não fazendo parte do rol a idade avançada.

Segundo a visão extraída da norma, por mais avançada que seja sua idade, a pessoa que possua lucidez, tem plena aptidão para cuidar diretamente de seus negócios, bens e interesses, inclusive se quiser dispor de considerável volume de suas reservas patrimoniais em atividades de pura diversão e lazer, poderá fazê-lo sem que os descendentes ou outros eventuais futuros sucessores tenham direito de impedi-la (COELHO 2012, EBOOK, pg. 416).

No ano de 2003 foi publicada a Lei $n^{\circ} 10.741$, também conhecida como estatuto do idoso, microssistema que é um marco na evolução protetiva às pessoas que alcançaram a denominada terceira idade. A preocupação do legislador foi mais do que legítima, sobretudo ante a visão negativa que erroneamente recai às pessoas de idade avançada, que são associadas à dependência, fraqueza e improdutividade.

Acrescenta-se ainda o fato de que, de acordo com projeções do IBGE, no ano de 2039 a população idosa do Brasil ultrapassará, pela primeira vez, o número de crianças, e, no mundo, a população mundial com idade superior a 60 anos chegará a dois bilhões de pessoas até $2050^{4}$.

Dessa forma, a referida lei alcança importância fundamental como mais um meio protetivo aos direitos da personalidade dessa parcela da população, que deve ser encarada tanto em seu viés personalíssimo como enquanto convivente de uma sociedade plural, conforme leciona Bittar:

\footnotetext{
${ }^{4}$ De acordo com notícia veiculada no jornal da usp: https://jornal.usp.br/atualidades/em-2030-brasil-tera-aquinta-populacao-mais-idosa-do-mundo/ acesso 03 dez. 2019
} 
Na identificação da personalidade - e à luz da classificação já esboçada - divisamos diferentes componentes da estruturação física, psíquica ou moral da pessoa, conforme se refiram à sua condição de ser individual (tomado em si mesmo), ou de ser social (integrado à sociedade).

Nessa colocação, partimos da análise da natureza da pessoa humana e de sua composição extrínseca e intrínseca, tomando como referência a posição individual e a consideração no seio da sociedade.

No plano individual, esferas diferentes de bens integram a personalidade do ser, alguns insuscetíveis de atingimento pelo mundo exterior - em função de interesses maiores (como a vida a honra) - outros, ao revés, passíveis de ingresso no comércio jurídico, dentro do direito de disposição exclusivo de seu titular (imagem, criação intelectual). No âmbito da consideração social, outro grupo de bens componentes do patrimônio individual (como reputação, a dignidade pessoal) merece também o amparo jurídico, para feito de evitar-se turbações ou por parte de outras pessoas. (BITTAR 2015, EBOOK pg. 1552)

O Estatuto do Idoso, logo nos artigos $1^{\circ}$ e $2^{\circ}$, estabelece os sujeitos que estão protegidos pelo diploma normativo, inclusive destacando os direitos fundamentais a estes conferidos, veja-se:

Art. $1^{\circ}$ É instituído o Estatuto do Idoso, destinado a regular os direitos assegurados às pessoas com idade igual ou superior a 60 (sessenta) anos.

Art. $2^{\circ} \mathrm{O}$ idoso goza de todos os direitos fundamentais inerentes à pessoa humana, sem prejuízo da proteção integral de que trata esta Lei, assegurando sê-lhe, por lei ou por outros meios, todas as oportunidades e facilidades, para preservação de sua saúde física e mental e seu aperfeiçoamento moral, intelectual, espiritual e social, em condições de liberdade e dignidade.

Da redação do artigo $2^{\circ}$ recém-citado resta inequívoco o cunho protetivo, inclusive em seus direitos da personalidade aos que atingiram a faixa etária referida. Destaca-se ainda que o envelhecimento é algo inerente à natureza humana. Então, inconcebível seria a ideia de diminuição ou perda de direitos inerentes à personalidade ante o passar dos anos, pelo contrário, outro não poderia ser o entendimento senão pela proteção ainda maior de um grupo de pessoas que por sua própria condição está em um momento de maior vulnerabilidade.

Os direitos da personalidade são os direitos subjetivos da pessoa de defender o que lhe é próprio, ou seja, a vida, a integridade, a liberdade, a sociabilidade, a reputação ou honra, a imagem, a privacidade, a autoria etc. (SILVA, 2012, EBOOK, pg. 48).

Apesar de grande importância o Código Civil de 2002, no capítulo a eles dedicado, pouco desenvolveu a temática, embora fiel ao objetivo primordial a preservação do respeito à dignidade da pessoa humana, assim como, a vários outros direitos protegidos constitucionalmente, como se pode ver em seus artigos 948 e 951, relativos ao direito à vida, 
nos artigos. 949 e 950, concernentes à integridade física e psíquica, no artigo. 953, alusivo ao direito à honra, e no artigo. 954, sobre a liberdade pessoal. (SILVA, 2012, EBOOK, pg. 48).

Interessante citar ainda o enunciado ${ }^{\circ} 274$, aprovado na IV Jornada de Direito Civil: Os direitos da personalidade, regulados de maneira não-exaustiva pelo Código Civil, são expressões da cláusula geral de tutela da pessoa humana, contida no art. $1^{\circ}$, inc. III, da Constituição (princípio da dignidade da pessoa humana). Em caso de colisão entre eles, como nenhum pode sobrelevar os demais, deve-se aplicar as técnicas da ponderação e proporcionalidade.

O capítulo do código tocante aos direitos da personalidade, afora os princípios gerais mencionados, refere-se especificamente ao direito e proteção à integridade do corpo da pessoa, a seu nome e imagem e à inviolabilidade da sua vida privada na condição de pessoa natural. Não é exaustiva a enumeração legal, pois a ofensa a qualquer modalidade de direito da personalidade, dentro da variedade que a matéria propõe, pode ser coibida, segundo o caso concreto (VENOSA, 2013, pg. 201)

Isto posto, é notória a participação ativa dos idosos nas atividades sociais. E, sobretudo na atual sociedade de consumo, onde a aquisição e/ou utilização de produtos e serviços por seus destinatários finais (consumidores) acompanha proporcionalmente o crescimento populacional e o aumento de expectativa de vida dos idosos. Assim, faz-se necessário que o Direito do Consumidor aponte soluções para os conflitos que surgem dessas relações, sobretudo considerando a hipervulnerabilidade dos idosos enquanto consumidores, em especial, na busca por uma proteção efetiva de seus direitos da personalidade.

\section{O RECONHECIMENTO DA HIPERVULNERABILIDADE DO IDOSO COMO MANIFESTAÇÃO DOS DIREITOS DA PERSONALIDADE}

A vulnerabilidade do consumidor é o ponto de partida do viés protetivo do Código de Defesa do Consumidor, em virtude dessa vulnerabilidade é que se reconhece no consumidor o polo mais fraco da relação, sobretudo nos dias atuais onde conglomerados empresariais comandam a cadeia produtiva, a distribuição e o comércio desde produtos essenciais até os mais supérfluos.

De acordo com Flávio Tartuce (TARTUCE, NEVES, 2017 pg. 33) a realidade da sociedade de consumo, não há como afastar tal posição desfavorável, principalmente se forem 
levadas em conta as revoluções pelas quais passaram as relações jurídicas e comerciais nas últimas décadas. Explica, ainda, que todo consumidor é sempre vulnerável, sendo esta uma característica intrínseca à própria condição de destinatário final do produto ou serviço.

Percebe-se assim, que o princípio da vulnerabilidade é o alicerce que fundamenta a existência e aplicação do direito do consumidor. O artigo 4, I, do CDC estabeleceu o "reconhecimento da vulnerabilidade do consumidor no mercado de consumo" entre os princípios informadores da Política Nacional das Relações de Consumo. A existência de direito do consumidor justifica-se pelo reconhecimento da vulnerabilidade do consumidor, pois é esta que determina ao direito que se ocupe da proteção do consumidor (MIRAGEM, 2016).

Claudia Lima Marques (MARQUES, 2010, pg. 197) por sua vez explica que a vulnerabilidade trata de um princípio básico do CDC. Um estado da pessoa, uma situação inerente de risco ou um sinal de confrontação excessiva de interesses identificados no mercado, uma situação permanente ou provisória, individual ou coletiva que fragiliza, enfraquece o sujeito de direitos desequilibrando a relação, subdividindo-a em 3 espécies:

Vulnerabilidade técnica - Ausência de conhecimentos específicos sobre o objeto que está sendo adquirido pelo comprador.

Vulnerabilidade fática - A vulnerabilidade fática é a desproporção de forças, intelectuais, econômicas que caracteriza a relação de consumo.

Vulnerabilidade jurídica ou científica - Foi identificada e protegida pela corte alemã, nos contratos de empréstimo bancário e financiamento. É a falta de conhecimento jurídico específicos.

Para além da vulnerabilidade, há que se destacar casos de consumidores em que essa característica é ainda mais acentuada, chamado de hipervulnerabilidade, por ostentarem condições específicas, dentro desse grupo encontram-se os idosos.

Acerca do tema, Antônio Herman de Vasconcellos e Benjamin explica que existem consumidores que são mais vulneráveis que outros, ou seja, cuja vulnerabilidade é superior à média. São os consumidores ignorantes e de pouco conhecimento, de idade pequena ou avançada, de saúde frágil, bem como aqueles cuja posição social não lhes permita avaliar com adequação o produto ou serviço que estão adquirindo (BENJAMIM,2004, pg. 370).

É fato indubitável que a condição de idoso é acompanhada de dificuldades no pleno exercício das faculdades, especialmente no que diz respeito às condições de saúde a 
capacidade de raciocínio, locomoção, labor e diversas outras são gradativamente afetadas pela inevitável degeneração causada pelo curso do tempo, fato jurídico a que todos estão sujeitos. Foi a partir dessas noções que surgiu o conceito de solidariedade intergeracional. (VERBICARO, 2019, pg. 41).

A vulnerabilidade agravada ou hipervulnerabilidade tem justificativa Constitucional, por força do princípio da dignidade da pessoa humana - especificamente as crianças, os adolescentes, os portadores de deficiências e os idosos -, aplicando-o como solução para a tutela de pessoa consumidora no negócio jurídico em face do mínimo existencial, uma vez que o citado princípio "institui cláusula geral de tutela da dignidade da pessoa humana, impondo reconhecimento e influência de interesses não patrimoniais sobre relações privadas" (PINHEIRO e DETROZ, 2012, p. 128).

Além da força do princípio da dignidade humana outro fundamento para o reconhecimento da hipervulnerabilidade é a isonomia constitucional, ela justifica alguns privilégios aos consumidores que necessitem de proteção especial, tidos como hipervulneráveis, caso de idosos, portadores de deficiências, crianças e adolescentes, que merecem proteção por duplo ou triplo motivo (TARTUCE, NEVES 2017, pg. 44).

Tratando mais especificamente da lei consumerista e sua proteção a consumidores com vulnerabilidade agravada, dentre esses os idosos, deve-se destacar que um dos objetivos do CDC é restabelecer o equilíbrio contratual da relação, que já nasce desequilibrada por figurarem em polos opostos as figuras do consumidor e do fornecedor. Quando se fala, pois, em consumidores hipervulneráveis, para os quais o desequilíbrio é maior, há que se intensificar essa proteção (NUNES, 2016, pg. 117).

Exatamente em virtude dessa necessidade de proteção intensificada é que Adalberto Pasqualotto explica que na hipervulnerabilidade é possível exigir do fornecedor um maior cuidado na formação desse vínculo com o consumidor e na sua execução, que pode não ser o mesmo de uma relação em que a hipervulnerabilidade não está presente (PASQUALOTTO, 2017, pg. 87).

Visando coibir quaisquer abusos em virtude da idade do consumidor, o CDC colacionou como prática abusiva a prevalência do fornecedor quanto ao consumidor em virtude, dentre outros fatores, de sua idade ${ }^{5}$.

\footnotetext{
${ }^{5}$ Art. 39. É vedado ao fornecedor de produtos ou serviços, dentre outras práticas abusivas:

IV - prevalecer-se da fraqueza ou ignorância do consumidor, tendo em vista sua idade, saúde, conhecimento ou condição social, para impingir-lhe seus produtos ou serviços;
} 
Dessa maneira, o fornecedor não poderá se aproveitar das excepcionais vulnerabilidades do consumidor para impor-lhe produtos ou serviços. Vários critérios são levados em consideração pela norma, como a idade (quer se trate de criança ou idoso); condição social (já que uma pessoa mais simples terá mais dificuldade de compreender novas tecnologias, podendo ser vítimas dos maus fornecedores); conhecimento (os analfabetos, por exemplo, terão dificuldades na contratação, sendo alvos fáceis também dos maus fornecedores) e a saúde (muito comum a prática dos hospitais de exigirem garantias abusivas da família) (GARCIA, 2016, pg. 327).

Importante destacar que a adoção do critério de hipervulnerabilidade do idoso é acolhida pela doutrina e pela jurisprudência. A doutrina brasileira ao enquadrar o consumidor idoso no grupo abrangido aos hipervulneráveis, estritamente visou a sua proteção no princípio da dignidade da pessoa humana, resguardando os aspectos patrimoniais e existenciais (ROSA; BERNARDES; FÉLIX, 2017, pg.552).

Dentro do ordenamento jurídico brasileiro, a necessidade de visualizar a fragilidade do consumidor idoso e, principalmente, buscar meios de protegê-lo, alcança mais autores e chega aos juízes de modo a fazê-los perceber que em muitas situações é necessário cautela, análise e percepção nas suas decisões, possibilitando-os enxergar a debilidade destes consumidores nos casos concretos que passam a julgar. Neste sentido, há decisões que avaliaram a posição do consumidor idoso como sendo de fragilidade, de modo que é possível identificar na jurisprudência uma hipervulnerabilidade do consumidor idoso. (GAUDENCIO, 2016, pg.159).

Corroborando com a afirmação supra, destaca-se trecho do julgado (STJ - REsp: 1851310 RS 2019/0358170-9 $9^{6}$ ).

(...) Na espécie, ainda, há de se considerar que a vítima é pessoa idosa (fl. 34), o que denota sua hipervulnerabilidade, objeto da proteção do art. 39, também da Lei 8.078/90: (...) A necessidade de diferenciação da condição de determinadas categorias de consumidores, em função das condições pessoais e econômicas, é ilustrada também por Bruno Miragem, ao identificar a" vulnerabilidade agravada "dos idosos e das crianças. Como visto, esta proteção diferenciada ao idoso decorre da própria fragilidade da condição humana na idade madura frente aos

\footnotetext{
${ }^{6}$ BRASIL. Superior Tribunal de Justiça - STJ- REsp: 1851310 RS 2019/0358170-9, Relator: Ministro MARCO AURÉLIO BELLIZZE, Data de Publicação: DJ 18/12/2019. Disponível em: https://scon.stj.jus.br/SCON/decisoes/toc.jsp?livre=1851310\&processo=1851310.NUM.\&b=DTXT\&thesaurus= JURIDICO\&p=true . Acesso 20 jul. 2020
} 
avanços da ciência, responsáveis pelo aumento da expectativa de vida e da complexidade das relações negociais standartizadas. (...)

Desta feita, o princípio da hipervulnerabilidade se consubstancia como um meio de assegurar o respeito, observância e prevalência dos Direitos da Personalidade do idoso, ao resguardar para esse grupo um alcance protetivo ainda maior, buscando, dessa forma, evitar a afronta à imagem, honra, saúde, integridade física, dos idosos quando na relação de consumo.

Acerca dos Direitos da Personalidade, em que pese estarem expresso no código civil, devem ser analisados em consonância com a Constituição Federal, bem como outros diplomas normativos tal qual o Código de Defesa do Consumidor e o Estatuto do Idoso. O intento protetivo dos Direitos da Personalidade, não é estanque, pelo contrário, partindo de uma premissa maior, a Constituição Federal e pulverizando por outros diplomas normativos, devem ser complementares.

Nessa acepção, explica Bittar que os direitos da personalidade são tutelados no ordenamento jurídico em diferentes campos: Constitucional, Penal e Civil, desfrutando, assim, de estatutos diversos, como vimos, em função do prisma analisado. Desse modo, no âmbito constitucional, disciplinados como liberdades públicas recebem regulamentação como direitos de cunho fundamental no Estado, fluindo de garantias específicas, previstas no contexto da Carta Magna, na defesa da dignidade da pessoa diante dos poderes públicos. $\mathrm{Na}$ esfera civil, perfaz-se a proteção por meio de instrumentos de preservação da pessoa no circuito privado, contra investiduras de particulares e na salvaguarda de seus mais íntimos interesses, dentro da liberdade e da autonomia própria de cada ser. (BITTAR, 2015, pg. 1552 EBOOK).

Não obstante, em que pese a existência de princípios específicos que tutelam interesses de consumidores hipervulneráveis, não raras são as situações em que os idosos se tornam vítimas de fornecedores que, se aproveitando de fatores inerentes a esse grupo, como idade, memória, dificuldade de raciocínio, praticam atos que abusam e aviltam contra a dignidade e direitos da personalidade, sobretudo em contratos de empréstimos bancários, que possuem especificidades e termos demasiadamente técnicos.

\section{O CONSUMIDOR IDOSO NOS CONTRATOS DE EMPRÉSTIMO BANCÁRIO}

Nos últimos anos houve uma facilitação de acesso a créditos bancários, contudo, a educação financeira dos cidadãos não acompanhou esse aumento exponencial. A soma desses 
fatores, crédito facilitado e ausência de educação e consciência financeira ocasionam o superendividamento de parcela da população ${ }^{7}$.

Pode-se dizer que o superendividamento é um fenômeno próprio do capitalismo moderno, afeta direta e sensivelmente sujeitos das mais variadas classes sociais, níveis econômicos e perfis intelectuais. Forçadas a consumir para poder se inserir socialmente, as pessoas estão perdendo o controle e se endividando além de seus limites (BRITO; ARAÚJO, 2017, pg. 165).

O mencionado fenômeno há tempos se manifesta como um problema que vai muito além de interesses particulares, afetando toda a sociedade. A professora Cláudia Lima Marques, assim conceitua: "O superendividamento pode ser definido como impossibilidade global do devedor-pessoa física, consumidor, leigo e de boa-fé, de pagar todas as suas dívidas atuais e futuras de consumo (excluídas as dívidas com o Fisco, oriundas de delitos e de alimentos) em um tempo razoável com sua capacidade atual de rendas e patrimônio ${ }^{8 \%}$.

O idoso também tem experimentado os dissabores do superendividamento ${ }^{9}$, não estando imune à caraterística do consumismo, que marca a sociedade contemporânea. Quer seja pelo excessivo consumo ou até mesmo por recursos financeiros exíguos ante os baixos valores percebidos a título de proventos, é que o idoso se vê em condição de endividamento, que finda por atraí-lo para os contratos de empréstimo consignado.

Acerca dos recursos financeiros oriundo de proventos, dados constantes no sítio oficial do INSS apontam que o valor médio percebido pelos aposentados por tempo de contribuição é de $\mathrm{R} \$ 2.466,23$ para os homens e $\mathrm{R} \$ 2.087,58$ para as mulheres, sendo que tais valores são ainda menores em caso de aposentadorias por idade ou por invalidez ${ }^{10}$.

7 De acordo com o IDEC (Instituto Brasileiro de Defesa do Consumidor), o superendividado é aquele cuja renda está tão comprometida, que perdeu a capacidade de pagar suas dívidas, a ponto de colocar em risco sua subsistência, ou seja, de quitar contas básicas como alimentação e moradia. O instituto estima que 30 milhões de brasileiros estejam nesse grupo de devedores. Disponível em: https://idec.org.br/idec-naimprensa/superendividamento-saiba-o-que-e-e-como-fugir

8 Prevenção e tratamento do superendividamento disponível em: http://www.ufrgs.br/ocsc/mirror/362116752af7cc51043aa5f31ff17f25/8.pdf Acesso em: 17 jul. 2020

9 Dados do Serasa mostram que de abril de 2018 a abril de 2019 o número de pessoas com mais de 65 anos com o nome registrado no cadastro de devedores aumentou 45\%, disponível em: https://www.camara.leg.br/noticias/561529-estudos-apontam-endividamento-de-idosos-e-empobrecimento-demulheres-mais-velhas/ Aceso em: 17 jul. 2020

${ }^{10}$ Dados emanados $\quad$ pelo INSS, disponível em: http://sa.previdencia.gov.br/site/2019/01/Beps112018_trab_FINAL.pdf Acesso em 18 jul 2020 
A insuficiência de recursos financeiros pode motivar contratação de créditos bancários, em algumas situações, a contratação do crédito é afetada por circunstâncias concretas, que incidem na formação da relação jurídica (e não sobre o consumidor em si), mas que efetivamente agravam a já reduzida liberdade negocial do consumidor. É o caso dos empréstimos firmados para atender necessidades essenciais da pessoa humana, hipóteses em que o crédito assume a feição de serviço essencial. Quando a contratação do crédito deixa de ser uma opção ao incremento do bem-estar, para ser a única alternativa viável frente à necessidade, não há propriamente liberdade de escolha (OLIVEIRA,2014, pg. 63).

Cristiano Heineck Schmitt expõe que especialmente na seara contratual que se observa uma intensa vulnerabilidade do consumidor idoso perante o fornecedor, daí falarmos em hipervulnerabilidade como um paradigma a ser adotado na proteção do indivíduo mais fragilizado (SCHMITT, 2009, pg. 45).

Um dos fatores que pode ter corroborado com o superendividamento dos idosos foi a Lei 10.820/2003, que estabeleceu o denominado Crédito Consignado, um crédito facilitado no qual já há um desconto em "folha”, quer seja da remuneração ou dos proventos percebidos pelo contratante. O referido diploma normativo possibilitou ao idoso, titular de benefício previdenciário, autorizar a realização de consignado vinculado ao seu benefício, permitindo assim a concessão de crédito:

Art. $6^{\circ}$ Os titulares de benefícios de aposentadoria e pensão do Regime Geral de
Previdência Social poderão autorizar o Instituto Nacional do Seguro Social - INSS a
proceder aos descontos referidos no art. $1^{\underline{0}}$ e autorizar, de forma irrevogável e
irretratável, que a instituição financeira na qual recebam seus benefícios retenha,
para fins de amortização, valores referentes ao pagamento mensal de empréstimos,
financiamentos, cartões de crédito e operações de arrendamento mercantil por ela
concedidos, quando previstos em contrato, nas condições estabelecidas em
regulamento, observadas as normas editadas pelo INSS. Lei 10.820/2003, (grifo
nosso).

O crédito consignado teve um sucesso enorme, estimulado também por uma campanha bastante agressiva de publicidade pelos bancos. Além da publicidade normal foram empregados clipes na televisão onde bem conhecidos atores, também já em idade avançada, aconselharam este "crédito amigo" aos aposentados. Também se trabalhou com medos específicos de pessoas idosas (solidão, saúde) e finalmente se usou da autoridade de pessoas famosas reconhecidas. A tendência de exagerar aspectos positivos e esconder problemas do crédito levou a alguns processos jurídicos (DOLL; CAVALLAZZI, LUNARDELLI, 2016, pg.324). 
Cristiano Heineck Schmitt destaca que o atual mundo consumerista vê na população idosa uma grande possibilidade de geração de lucros. A publicidade contemporânea vem focando nesse ramo da sociedade, o que não acontecia antigamente (SCHMITT, 2014, p. 9091). Apenas a partir do século XXI que o idoso passou a ser observado como uma alternativa de lucro, diante do fato de os idosos terem suas rendas aumentadas com o decorrer dos anos. Tal fato pode ser apontado como outra relevante causa para o superendividamento (SCHMITT, 2014, pg. 137-138).

A par da facilidade dessa modalidade, o crédito consignado pode endividar uma pessoa de forma que sua subsistência reste prejudicada. Os idosos se tornaram o novo alvo deste mercado uma vez que o desconto direto de parcelas do empréstimo em sua aposentadoria é uma forma muito segura de quitação do mesmo. Com esse novo mercado em vista, houve um aumento de publicidade destes empréstimos voltados a idosos, muitas vezes usando celebridades que inspiram confiança naqueles (OLIVEIRA, 2010, pg. 502).

O que, à primeira vista, parece ser muito positivo, mostra-se - analisando mais criteriosamente- como uma "faca de dois gumes", pois o grande risco é que após a "lua de mel do crédito" chega a grande ressaca, principalmente para os consumidores idosos. Nossa análise demonstrou que os idosos são, de fato, um grupo altamente vulnerável e, por isso, é necessário pensar em medidas protetivas, medidas que ajudem a resolver os problemas decorrentes como um superendividamento já existente, e medidas educacionais (DOLL; CAVALLAZZI, LUNARDELLI, 2016, pg. 338)

Além dos riscos inerentes ao superendividamento daqueles que, sem a devida educação financeira se utilizam de créditos "facilitados", a situação se agrava demasiadamente ante a prática de fornecimentos de créditos de forma abusiva, no que tange a juros e outros encargos, à forma de contratação, à ausência de informação, à publicidade agressiva, sendo que tais problemas se agravam quando analisados os idosos como contratantes e consumidores endividados.

Os dados de possíveis práticas abusivas nas concessões de tais créditos são alarmantes, havendo aumento expressivo entre os anos de 2017 e 2018, passando de 63.404 reclamações, para 75.529, conforme informações repassadas pelo INSS ao Departamento de 
Proteção e Defesa do Consumidor(DPDC) da Secretaria Nacional do Consumidor $(\text { Senacon })^{11}$.

Quase 150 mil manifestações de aposentados e pensionistas do país relatam casos de possíveis práticas abusivas de empresas financeiras. A partir da análise de resultados da lista apresentada pelo Instituto Nacional de Seguro Social (INSS) do Ministério da Economia, a Secretaria Nacional do Consumidor (Senacon), do Ministério da Justiça e Segurança Pública, definiu a instauração de processos administrativos relacionados às dez empresas com mais reclamações registradas sobre empréstimos consignados, empréstimos não autorizados e questão de reserva de margem para cartão de crédito ${ }^{12}$.

Um dos objetivos do estatuto do idoso é justamente evitar abusos, assegurando a observância e manutenção da dignidade bem como dos direitos de sua personalidade, nessa lógica destacam-se os artigos $4^{\circ}$ e $5^{\circ}$ :

\footnotetext{
Art. $4^{\circ}$ Nenhum idoso será objeto de qualquer tipo de negligência, discriminação, violência, crueldade ou opressão, e todo atentado aos seus direitos, por ação ou omissão, será punido na forma da lei.

$\S 1^{\circ}$ É dever de todos prevenir a ameaça ou violação aos direitos do idoso.

$\S 2^{\underline{o}}$ As obrigações previstas nesta Lei não excluem da prevenção outras decorrentes dos princípios por ela adotados.

Art. 5ํำ A inobservância das normas de prevenção importará em responsabilidade à pessoa física ou jurídica nos termos da lei.
}

Uma existência digna é assegurada constitucionalmente a todos indivíduos. Desse modo, o constituinte buscou defender no artigo $5^{\circ}$, XXII não o consumo em si, mas a pessoa do consumidor, como forma de assegurar ao ser humano a fonte de preocupação do Direito, tal preocupação deve ser ainda mais acentuada quando se tratar de contratações de empréstimos, sobretudo no que tange aos idosos, hipervulneráveis por sua natureza.

Em tempo, e com fito de exemplificar a atuação do judiciário nesse tema, convém destacar o seguinte julgado que evidencia a vulnerabilidade do consumidor idoso bem como o dever de informar por parte do fornecedor:

CONTRATOS DE EMPRÉSTIMOS CONSIGNADOS. REFINANCIMENTO POR TELEFONE. AUSÊNCIA DE INFORMAÇÕES SOBRE A

\footnotetext{
11 Reportagem veiculada no site: https://oglobo.globo.com/economia/defesa-do-consumidor/bancos-seraoinvestigados-por-pratica-abusiva-na-concessao-de-emprestimo-consignado-idosos-23818801 acessado em 16 dez. 2019

${ }^{12}$ Reportagem veiculada no site: https://www.justica.gov.br/news/collective-nitf-content-1563994715.9 acessado em 17 dez. 2019.
} 
CONTRATAÇÃO. VULNERABILIDADE DA AUTORA - IDOSA. RETORNO AO STATUS QUO ANTE. SITUAÇÃO PREJUDICIAL À CONSUMIDORA. DANOS MORAIS CONFIGURADOS. A par da documentação constante nos autos, não se tem dúvida de que a contratação dos novos empréstimos consignados ocorreu por meio de contato telefônico, assim como presente a ocorrência de falha no dever de informação ao consumidor quanto às condições dos novos contratos. Nessa linha, as partes devem retornar ao status quo ante e, causando a situação transtornos à autora, os danos sofridos devem ser indenizados. A quantia de $\mathrm{R} \$ 2.500,00$ (dois mil e quinhentos reais) mostra-se satisfatória para reparar os danos causados e atender ao caráter punitivo a fim de impedir o réu de cometer novos ilícitos, seja com a autora ou com outros clientes. RECURSO PARCIALMENTE PROVIDO. TJ-RS - Recurso Cível: 71003923018 RS, Relator: Lucas Maltez Kachny, Data de Julgamento: 28/05/2013, Primeira Turma Recursal Cível, Data de Publicação: Diário da Justiça do dia 31/05/2013. $(\text { grifei })^{13}$

O crédito consignado não é o único tipo facilitado disponível na sociedade contemporânea. Para melhor contextualizar, cita-se a título de exemplo, os terminais de autoatendimento nos quais, por vezes, a primeira opção é empréstimo a "apenas um click".

Terminais de autoatendimento são ferramentas que facilitam a vida daqueles que utilizam, porém, são também ferramentas delicadas e complexas, sobretudo para idosos e pessoas com poucas instruções, as quais não possuem conhecimentos para se auto atenderem como se bancários fossem.

Novamente, com o fito exemplificativo, analisa-se uma decisão acerca da temática:

APELAÇÃO CÍVEL. DIREITO DO CONSUMIDOR. REFINANCIAMENTO. AUSENCIA DE CONTRATAÇÃO. 1 - A despeito de as contratações de empréstimos através de caixa eletrônico serem amplamente aceitas pelo ordenamento jurídico, também é certo que transações desse jaez não raro submetem o consumidor contratante a dissabores de enganos cometidos na utilização do serviço em razão da complexidade dos comandos digitais dos terminais eletrônicos, falha essa atribuível às instituições financeiras em geral. 2 No caso das renegociações e os rearranjos de contratos anteriores pela mesma via, estas carecem de transparência e clareza para o consumidor, dado que nestes há uma maior necessidade de detalhamento específico quanto aos termos, parâmetros e as consequências de tais operações, em obediência aos princípios norteadores das relações contratuais, especialmente aos princípios da função social do contrato, da boa-fé objetiva e do equilíbrio econômico, assim como em respeito à própria Resolução $\mathrm{n}^{\mathrm{o}} 4.283 / 2013$ do BACEN. 3 - Trata-se o autor de pessoa idosa e que, decerto, não ostenta familiaridade, como tantos outros consumidores idosos, com os mecanismos de transações em terminais eletrônicos, não sendo, ademais, crível que, após pagar quase a metade das prestações no valor de $\mathbf{R} \$ 377,00$ do empréstimo pactuado com juros de 2,22 a.m.(fls. 131/133 - indexador 000036), manifestasse a vontade de refinanciar o débito remanescente para pagar em 54 presatações de $\mathbf{R} \$ 420,00$ a $2,34 \%$ de juros ao mês. 4 - Por sua vez, a instituição financeira não comprovou a existência

${ }^{13}$ BRASIL. Tribunal de Justiça RS - TJRS - Recurso Cível: 71003923018 RS Disponível em: https://www.tjrs.jus.br/novo/buscas-solr/?aba=jurisprudencia\&q=\&conteudo_busca=ementa_completa. Acesso em: 20 jul. 2020 
de qualquer das excludentes de responsabilidade, previstas no artigo $14, \S 3^{\circ}$ do Código de Defesa do Consumidor, de forma a afastar a sua responsabilização pela falha na prestação do serviço. 5 - Assim, deve perseverar a condenação imposta na sentença, devendo a parte ré, a partir do restabelecimento do contrato originário de $\mathrm{n}^{\mathrm{o}}$ 000147869101, restituir ao autor, na forma simples, os descontos indevidamente efetuados, entendidos como tais a fração que exceder às parcelas originalmente pactuadas, de $\mathrm{R} \$ 377,00$, com incidência de correção monetária a contar do desembolso e juros de mora a partir da citação...." TJ-RJ - APL: 00130117120178190204, Relator: Des(a). HELENO RIBEIRO PEREIRA NUNES, Data de Julgamento: 19/11/2019, QUINTA CÂMARA CÍVEL ${ }^{14}$.

É certo que aqueles que são vítimas de contratações de crédito abusivas, com desrespeito às normas que regem a temática e aos princípios da boa-fé, da segurança, da informação veem atingidos negativamente, não apenas seus direitos patrimoniais, mas também os de personalidade.

Conforme exposto várias decisões enfrentaram práticas abusivas na concessão de crédito para idoso, valendo novamente de um exemplo, cita-se decisão oriunda do processo 1004461-83.2018.8.26.0481 do TJ/SP, na qual a houve condenação da Crefisa. No caso citado a financeira cobrou de um homem de 86 anos e com condição socioeconômica vulnerável juros que ultrapassaram $1.000 \%$ (mil por cento) ao ano. Com voto vencedor, o desembargador Roberto Mac Cracken destacou que os juros cobrados foram de "proporções inimagináveis". Na decisão, foi determinada a readequação das taxas, devolução em dobro dos valores cobrados em excesso bem como pagamento de indenização por dano moral ${ }^{15}$.

Tais ações são ainda mais reprováveis quando praticados contra idosos, posto que os fornecedores de créditos se aproveitam da idade avançada da pessoa, da sua dificuldade de entendimento de contratos com redações rebuscadas e ambíguas, da insuficiência de recursos financeiros, bem como, de eventuais gastos elevados com despesas médico-hospitalares.

Em tempo, destaca-se que tramita atualmente no Senado Federal o projeto de lei PL $3.515 / 2015$, na qual versa acerca do tratamento do superendividamento dos consumidores e seria de suma importância para melhor regulamentar a matéria que fosse de imediato aprovado.

14 BRASIL- Tribunal de Justiça RJ- TJRJ - APL: 00130117120178190204. Disponível em: http://www4.tjrj.jus.br/EJURIS/ProcessarConsJuris.aspx?PageSeq=0\&Version=1.1.10.0 acesso em 20 jul. 2020 ${ }_{15}$ Disponível em: https://julianaelsnerkoch.jusbrasil.com.br/noticias/770622543/crefisa-e-condenada-por-cobrarjuros-abusivos-de-1000-ao-ano-de-idoso-pobre?ref=serp 
O projeto foi apresentado em 04/11/2015 e possui como ementa: "Altera a Lei $\mathrm{n}^{\circ}$ 8.078, de 11 de setembro de 1990 (Código de Defesa do Consumidor), para aperfeiçoar a disciplina do crédito ao consumidor e dispor sobre a prevenção do superendividamento. ${ }^{16,}$

Dessa feita, em que pese a importância do acesso ao crédito para determinadas situações tal acesso não pode acarretar dissabores aqueles que o contratam, tampouco ser responsável por um superendividamento de parcela da população com valores que por vezes se tornam impagáveis.

A situação se agrava ainda mais quando além do risco ao superendividamento há relatos de possíveis práticas abusivas de empresas financeiras em contratos de crédito, atingindo direitos fundamentais de idosos, contrariando seus direitos da personalidade, avultando contra sua dignidade, honra, imagem, saúde física e psíquica sendo, portanto, passíveis de responsabilização por danos materiais e morais.

\section{CONSIDERAÇÕES FINAIS}

A proteção do consumidor fora elencada no Título II da Constituição Federal Direitos e Garantias Fundamentais - convergindo para a promulgação do CDC no início da década de 90 .

No intuito de assegurar a igualdade material, o Estatuto do Idoso buscou efetivar e garantir os direitos da personalidade desse grupo social, reconhecendo suas características e peculiaridades.

Contudo, em que pese a atuação do Constituinte, bem como das legislações infraconstitucionais, o que se pôde constatar é que não raras vezes os idosos padecem ante práticas abusivas de fornecedores, em especial no que tange aos créditos bancários, infamando direitos da personalidade, como imagem, honra, saúde física e mental.

A facilitação de acesso a créditos bancários, sem a evolução da educação financeira e sem uma fiscalização mais rigorosa da regulação tem ocasionado elevado nível de superendividamento de parcela da população, dentre os quais estão insertos os idosos.

Os números apontados no presente artigo demonstraram que com o advento da Lei 10.820/2003, que trouxe hipóteses de crédito consignado para aposentados e pensionistas, acarretou também enorme espaço para práticas abusivas por parte das instituições financeiras.

\footnotetext{
${ }^{16}$ Disponível em: https://www25.senado.leg.br/web/atividade/materias/-/materia/106773
} 
Nesse sentido, tendo amparo no Código de Defesa do Consumidor, a utilização da plataforma Consumidor.gov e a atuação de instituições como, Instituto Brasileiro de Defesa do Consumidor e a Secretaria Nacional do Consumidor, se destacam como fonte protetiva dos consumidores hipervulneráveis destacados no presente estudo.

Não obstante, necessário se faz uma mudança na cultura consumerista bem como atualização na legislação, a exemplo do Projeto de Lei - PL 3.515/2015 - como forma de se poder concretizar alguns princípios elencados no código de defesa do consumidor como informação, educação, proteção contra publicidade abusiva e enganosa, prevenindo, dessa forma, a ocorrência de práticas abusivas como as ocorridas na concessão de alguns créditos bancários para aposentados e pensionistas.

\section{REFERÊNCIAS}

BENJAMIN, Antônio Herman de Vasconcellos. Código Brasileiro de Defesa do Consumidor comentado pelos autores do anteprojeto. Rio de Janeiro: Forense Universitária, 2004.

BITTAR, Carlos Alberto. Os Direitos da Personalidade. 8 ed. São Paulo: Saraiva,2015

BRASIL. Lei $n^{\circ}$ 10.406, de 10 de janeiro de 2002. Institui o Código Civil. Diário Oficial [da] República Federativa do Brasil. Disponível em: <http://www.planalto.gov.br/ccivil_03/leis/2002/110406.htm>. Acesso em: 04 ago. 2019.

Constituição Federal de 1988. Diário Oficial [da] República Federativa do Brasil. Disponível em: 〈http://www.planalto.gov.br/ccivil_03/constituicao/constituicao.htm>. Acesso em: 07 ago. 2019.

Código de Defesa do Consumidor. Lei no 8.078, de 11 de setembro de 1990. Dispõe sobre a proteção do consumidor e dá outras providências. Diário Oficial [da] República Federativa do Brasil. Disponível em: <http://www.planalto.gov.br/ccivil_03/leis/18078.htm>. Acesso: 07 fev. 2019.

BRITO, Rodrigo Toscano de; FÁBIO, José de Oliveira Araújo. Contratos, superendividamento e a proteção dos consumidores na atividade econômica. Revista Direito e Desenvolvimento, v. 5, n. 9, p. 165 - 204, 6 jun. 2017.

BUAES, Caroline Stumpf. Caderno de educação financeira: viver bem com o dinheiro que se tem Porto Alegre : Ed. UFRGS, 2015 Disponível em: http://www.ufrgs.br/ocsc/web/law/ acesso em: 10/03/2020.

CJF. Conselho da Justiça Federal. Enunciado 274. Os direitos da personalidade, regulados de maneira não-exaustiva pelo Código Civil, são expressões da cláusula geral de tutela da pessoa humana, contida no art. $1^{\circ}$, inc. III, da Constituição (princípio da dignidade da pessoa 
humana). Em caso de colisão entre eles, como nenhum pode sobrelevar os demais, deve-se aplicar a técnica da ponderação. 2006. Disponível em: <https://www.cjf.jus.br/enunciados/enunciado/219>. Acesso em: 07 fev. 2019.

CANOTILHO, J. J. Gomes; MENDES, Gilmar F.; SARLET, Ingo W.; STRECK, Lenio L. (Coords.). Comentários à Constituição do Brasil. São Paulo: Saraiva/Almedina, 2013.

CARVALHO. Diógenes Faria De. Garantias do consumo a importância da proteção do consumidor (super)endividado. Disponível em: https://www.conjur.com.br/2018-set05/garantias-consumo-importancia-protecao-consumidor-superendividado acessado em 17 dez. 2019

CASTILHO, Ricardo. Direitos humanos. 5. ed. São Paulo : Saraiva Educação, 2018.

COELHO, Fábio Ulhoa. Curso de Direito Civil, parte geral. São Paulo: Saraiva, 2012.

DOLL, Johannes; Cavallazzi, Rosangela Lunardelli. Crédito consignado e o superendividamento dos idosos. Revista de Direito do Consumidor. vol. 107. ano 25. p. 309-341. São Paulo: Ed. RT, set.-out. 2016.

FERNANDES, Bernardo Gonçalves. Curso de direito constitucional. 9. ed. rev. ampl. e atual. Salvador: Juspodium, 2017.

GARCIA, Leonardo de Medeiros. Código de Defesa do Consumidor Comentado: artigo por artigo. 13. Ed. Salvador: JusPODIVM, 2016.

GAUDENCIO. Aldo Cesar Filgueiras. (hiper)proteção contratual do consumidor: consolidação da defesa dos consumidores hipervulneráveis no direito brasileiro. Revista de Direito, Globalização e Responsabilidade nas Relações de Consumo. Brasília. v. 2, n. 1. p. 149-166. Jan/Jun. 2016

MARQUES, Claudia Lima. Comentários ao Código de Defesa do Consumidor. 3 ed. São Paulo: Revista dos Tribunais, 2010.

MIRAGEM, Bruno. Curso de direito do consumidor. 6 ed. São Paulo: Editora Revista dos Tribunais, 2016.

MORAES, Alexandre de. Direito constitucional.32 ed. São Paulo: Atlas, 2016.

NUNES, Camila. O tratamento do idoso no mercado de consumo: um hipervulnerável? Revista Direito UFMS, Campo Grande, MS, v. 1, n. 2, p. 109 - 130|jan./jun. 2016

OLIVEIRA, Andressa Jarletti Gonçalves de. Defesa judicial do consumidor bancário. 2014. 547 f. Dissertação (mestrado Direito das Relações Sociais) Universidade Federal do Paraná, disponível em: https://acervodigital.ufpr.br/bitstream/handle/1884/35217/R\%20$\% 20$ D $\% 20 \% 20$ ANDRESSA\%20JARLETTI\%20GONCALVES\%20DE\%20OLIVEIRA.pdf? sequence $=1$

OLIVEIRA, Stéphanie Assis Pinto. Responsabilidade das celebridades em campanhas publicitárias de crédito consignado destinadas a idosos. Revista Jurídica Cesumar - 
Mestrado, v. 10, n. 2 p. 495-504, jul./dez. 2010. disponível em: https://periodicos.unicesumar.edu.br/index.php/revjuridica/article/view/1603.

ORGANIZAÇÃO DAS NAÇÕES UNIDAS (ONU). Declaração Universal dos Direitos Humanos. https://nacoesunidas.org/wp-content/uploads/2018/10/DUDH.pdf Acesso em: 03 dez. 2019.

PASQUALOTTO, Adalberto; SOARES, Flaviana Rampazzo. Consumidor hipervulnerável: análise crítica, substrato axiológico, contornos e abrangência. Revista de Direito do Consumidor. vol. 113. ano 26. p. 81-109. São Paulo: Ed. RT, set.-out. 2017.

PINHEIRO, Rosalice Fidalgo e DETROZ, Derlaune. A hipervulnerabilidade e os direitos fundamentais do consumidor idoso no direito brasileiro. Revista de Direito Público contemporâneo, n. ${ }^{\circ}$ 71, pg. 109 a 148, 2012.

ROSA, Luiz Carlos Goiabeira; BERNARDES, Luana Ferreira; FÉLIX, Vinícius Cesar. O idoso como consumidor hipervulnerável na sociedade de consumo pós-moderna. In: Revista Jurídica da Presidência, Brasília. v. 18. n. 116. Out. 2016/Jan. 2017. p. 533-558.

SARLET, Ingo Wolfgang; MARINONI, Luiz Guilherme; MITIDIERO, Daniel. Curso de direito constitucional. 7. ed. São Paulo: Saraiva Educação, 2018.

SARMENTO, Daniel. Dignidade da pessoa humana: conteúdo, trajetórias e metodologia. Belo Horizonte: Fórum, 2016.

SCHMITT, Cristiano Heineck. Consumidores hipervulneráveis. São Paulo: Atlas, 2014. In SANTANA, Héctor Valverde; CHAGAS, Rebecca Lorena de Sousa. Crédito consignado e o superendividamento do consumidor idoso. REVISTA JURÍDICA ESMP-SP, V.16, 2018: $212-231$

SCMITT, Cristiano Heineck. A hipervulnerabilidade do consumidor idoso. Revista Direito e justiça: reflexões sócio jurídicas, v.10, n.14, abr. 2010, 47-76

SILVA, Regina Beatriz Tavares. Código Civil Comentado. 8 ed. São Paulo: 2012

TARTUCE, Flávio; NEVES, Daniel Amorim Assumpção. Manual de direito do consumidor: direito material e processual. 6. Ed. Rio de Janeiro: Forense; São Paulo: MÉTODO, 2017.

VENOSA, Sílvio de Salvo. Direito civil: parte geral 13. ed. - São Paulo: Atlas, 2013.

VERBICARO, Dennis; ARRUDA, Sergie Gerrits. A hipervulnerabilidade do consumidor idoso nas mensalidades dos planos de saúde em razão da idade na jurisprudência repetitiva do stj (RESP 1.568.244/RJ). Revista Direito em Debate, v. 28, n. 51, p. 34-48, 7 ago. 2019. 